\title{
InSAR assets in ground movements survey on abandoned coalfields
}

\author{
J Morel BRGM (French Geological Survey), France \\ M Foumelis BRGM (French Geological Survey), France \\ D Raucoules BRGM (French Geological Survey), France \\ S Lemal BRGM (French Geological Survey), France
}

\begin{abstract}
Rising groundwater in abandoned mines may result in ground movements at the surface overlying underground works. Feedbacks on several abandoned coalfields (e.g., France, Belgium and UK) show that significant uplift can occur, reaching in some cases up to several tens of centimetres. In the framework of its missions, the Post-mining Department of the French Geological Survey (BRGM) has the mandate of surveying French abandoned coalfields for potential ground movements. The most common used method for this mission is levelling, performed at a given frequency.

Mine water recovery is a process that can last several tens of years. With the goal to optimise the long-term survey, the levelling technique has been re-examined by considering: 1) the phenomenology and kinetics of ground movements expected, in relation to water recovery rates; 2) alternative geodetic technologies, specifically spaceborne Interferometric Synthetic Aperture Radar (InSAR).

An InSAR retro-analysis of ground movements, covering more than 20 years after mine activity ceasing, has thus been realised on a French abandoned coalfield aiming to: 1) extend ground movements detection capabilities in areas not covered by levelling; 2) compare InSAR analysis to levelling data to evaluate robustness of displacement measurements. This study was carried out using the entire archive of ERS, ENVISAT and Copernicus Sentinel-1 SAR data.

The InSAR analysis was able to highlight ground movements of a few millimetres/year, with the same order of precision than classical levelling methods. The observed ground displacement patterns expand well beyond the coalfield, indicating the influence of non-mining-induced phenomena as well. Natural factors, such as local geology (clay content) or surface morphology (e.g., riverbeds), seem to be correlated to areas exhibiting relatively higher displacement rates. Further studies are necessary to separate accurately the contribution of the different factors in the induced ground deformation.

The comparison of InSAR results with levelling measurements shows a notable correlation. It emphasises also the importance to verify the stability of levelling benchmarks, as they might be affected by a combination of mining and non-mining induced displacements. These results point out the necessity of being cautious when interpreting the origin of damages caused by ground movements.

Our findings offer perspectives for the application of satellite InSAR for long-term survey of ground movements on abandoned coalfields especially when the expected movements are relatively slow. The ability to cover a wide area, frequency of data availability, accuracy of the measured displacement rates and the opportunity to perform retro-analysis are strong assets in post-mining monitoring context.
\end{abstract}

Keywords: abandoned coalfields, ground movement survey, InSAR, levelling 


\section{Introduction}

The Nord-Pas de Calais coal basin is located in the North of France. It extends from East to West for approximately $100 \mathrm{~km}$ and a width of 10 to $20 \mathrm{~km}$ (Figure 1). The basin was exploited between 1750 and 1990 , for a total production of $2400 \mathrm{Mt}$.

Coal extraction, down to more than $1000 \mathrm{~m}$ deep, and along superimposed seams, has generated during the mining period subsidence that can reach in some places more than $20 \mathrm{~m}$.

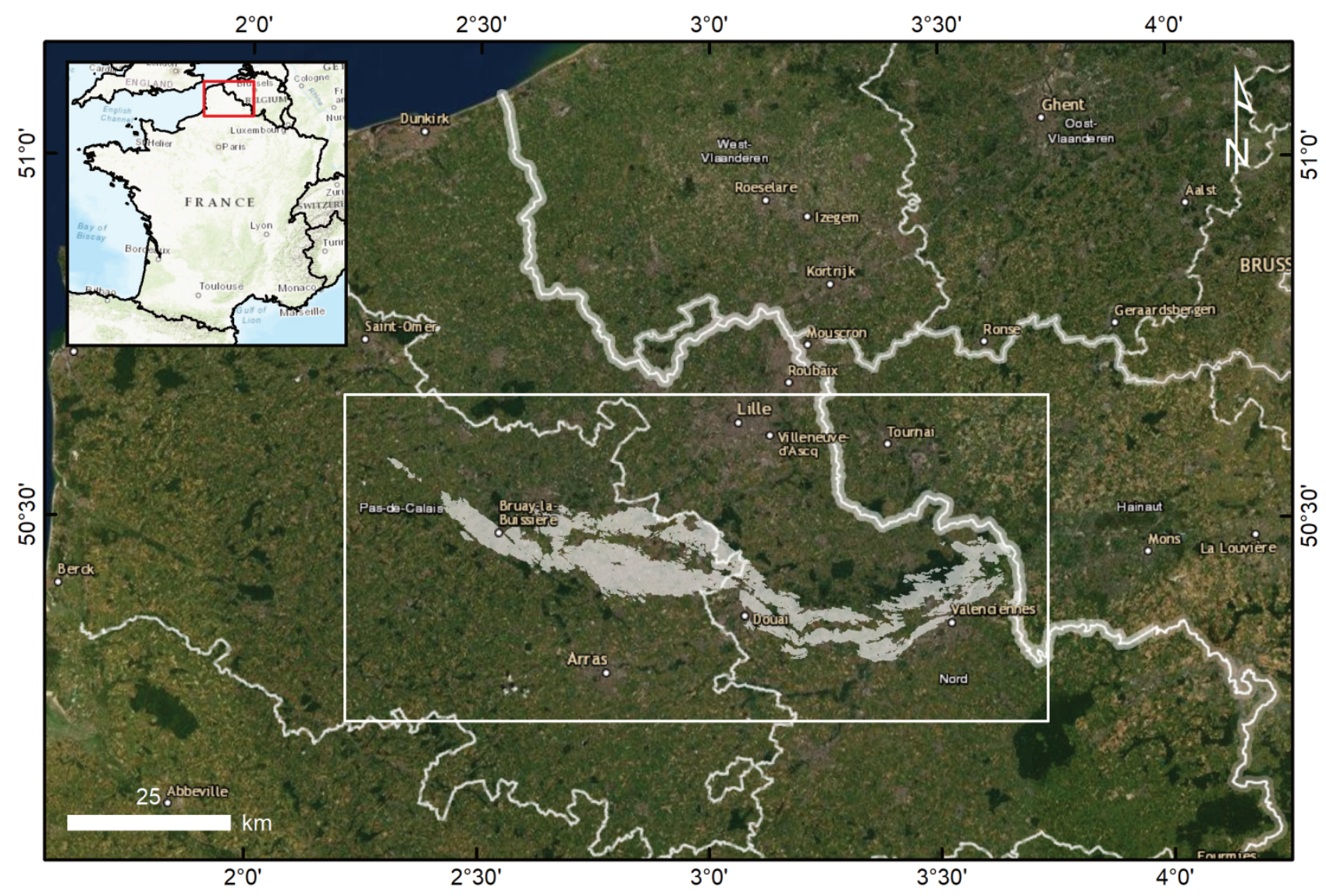

Figure 1 Location and configuration of the Nord-Pas de Calais Coalfield (underground mining works in grey)

At the end of the mining period, the termination of pumping operations initiated a progressive flooding of underground works, which will last more than one century. This flooding process may result in ground movements at the surface overlying underground works. After a transition phase, lasting a few years, during which residual subsidence occurs, ground uplift is generally observed (Banton et al., 2013, Devleeschouwer et al., 2008). This uplift finds its origin in two mechanisms (Herrero et al., 2012):

1. The dilation of underground caved works under pore pressure rise: this mechanism constitutes the main source of the uplift phenomenon, and will be related to the volume of underground works;

2. The swelling of clay material present in the overburden: the contribution of this second mechanism is much smaller and will concern essentially the first hundreds of meters below the surface.

Back experience on several abandoned coalfields (e.g., France, Belgium and UK) shows that this uplift can reach several tens of centimetres. Largest uplifts are generally observed on places where largest subsidence occurred during exploitation. Their kinetic is directly related to the one of rising groundwater.

Although of much smaller magnitude than subsidence during exploitation, ground movements induced by uplift may potentially cause limited damage to buildings. In order to survey these potential ground 
movements, five levelling lines of several kilometres long, mostly implemented in places where largest subsidence occurred during exploitation, are measured on a yearly basis.

The levelling lines provide high precision (of a few millimetres) measurements of ground movement. However, this technique stays spatially limited and does not offer the opportunity to detect ground movements at the coalfield scale. Mining-induced ground movement might occur also at places not covered by levelling. Moreover, the large extend of underground works might influence the stability, and as a consequence the representativeness of levelling benchmarks (reference points considered stable relatively to which the elevation measurements are done).

With the goal to optimise the long-term survey, an InSAR retro-analysis of ground movements, covering more than 20 years after mine activity ceasing, has been realised on the Nord-Pas de Calais coalfield. Our work aims to:

1. Extend ground movements detection capabilities in areas not covered by levelling;

2. Compare InSAR analysis to levelling data to evaluate robustness of displacement measurements by spaceborne geodetic techniques.

\section{Methodology}

Spaceborne SAR interferometry (InSAR) is a technique for processing of Synthetic Aperture Radar (SAR) images acquired from Earth Observation satellites. The interferometric processing of a sequence of SAR acquisitions imaged from approximately the same location at different dates allows the measurement of ground displacements, with a precision of a few millimetres. Such multi-temporal InSAR analysis is applicable for monitoring wide areas, while permitting the retro-analysis using already archived SAR data. The above facts make spaceborne InSAR a relevant technique to detect and monitor mine induced ground deformation.

For purpose of the current study the entire archive of ERS, ENVISAT and Copernicus Sentinel-1 SAR data were used (only descending orbits):

1. ERS: 246 images covering the period 1995-2000; 3 tracks were necessary to cover the entire coalfield;

2. ENVISAT: 141 images covering the period 2002-2010; 3 tracks were necessary to cover the entire coalfield;

3. Sentinel-1A: 164 IW TOPSAR images covering the period 2015-2018; a single track was enough to cover the entire coalfield.

The InSAR processing implemented is the interferometric stacking, which is based on the estimation of the average displacement rates by examining a set of successfully unwrapped differential interferograms (Foumelis et al., 2019). Processing was performed using the GAMMA software packages (Wegmüller et al., 2016). The ALOS Global Digital Surface Model (AW3D30) (http://eorc.jaxa.jp/ALOS/en/aw3d30/) was used to compensated for the topographic component. Considering the large amount of data that had to be managed, calculations were implemented on a Virtual Machine (VM) of the European Space Agency (ESA) Grid Processing on Demand (GPOD) service (https://gpod.eo.esa.int/).

More details on the methods used can be found in Hanssen (2001), Massonnet \& Feigl (1998) and Raucoules et al. (2007).

\section{$3 \quad$ Results}

The InSAR displacement rate map is provided with a spatial resolution of 60 metres. The displacement rates are expressed in millimetres per year over the considered period, referred to a benchmark point located in the town of Lille, far enough from the coalfield influence. As expected, the density of InSAR results is much higher in urban and suburban areas compared to vegetated lands (forest and/or agricultural fields), due to 
temporal decorrelation effects. Displacements are measured along the radar beam's line of sight (LOS). It is assumed that ground motion is essentially along the vertical direction.

\subsection{ERS and ENVISAT observation periods (1995-2000 and 2002-2010)}

A significant subsidence of $4 \mathrm{~mm} /$ year can be noticed in the central region of the coalfield for the ERS observation period (1995-2000) (Figure 2). This phenomenon occurs a few years after the end of the exploitation and might be attributed to residual subsidence. During the following ENVISAT observation period (2002-2010), the subsidence in this central region is slower but still present ( $2 \mathrm{~mm} / \mathrm{year}$ ), despite the fact that residual subsidence is generally expected to end few years after exploitation.

Increase in subsidence rate can be observed on some isolated areas during the ENVISAT period, e.g., more than 12 years after the end of coal exploitation.
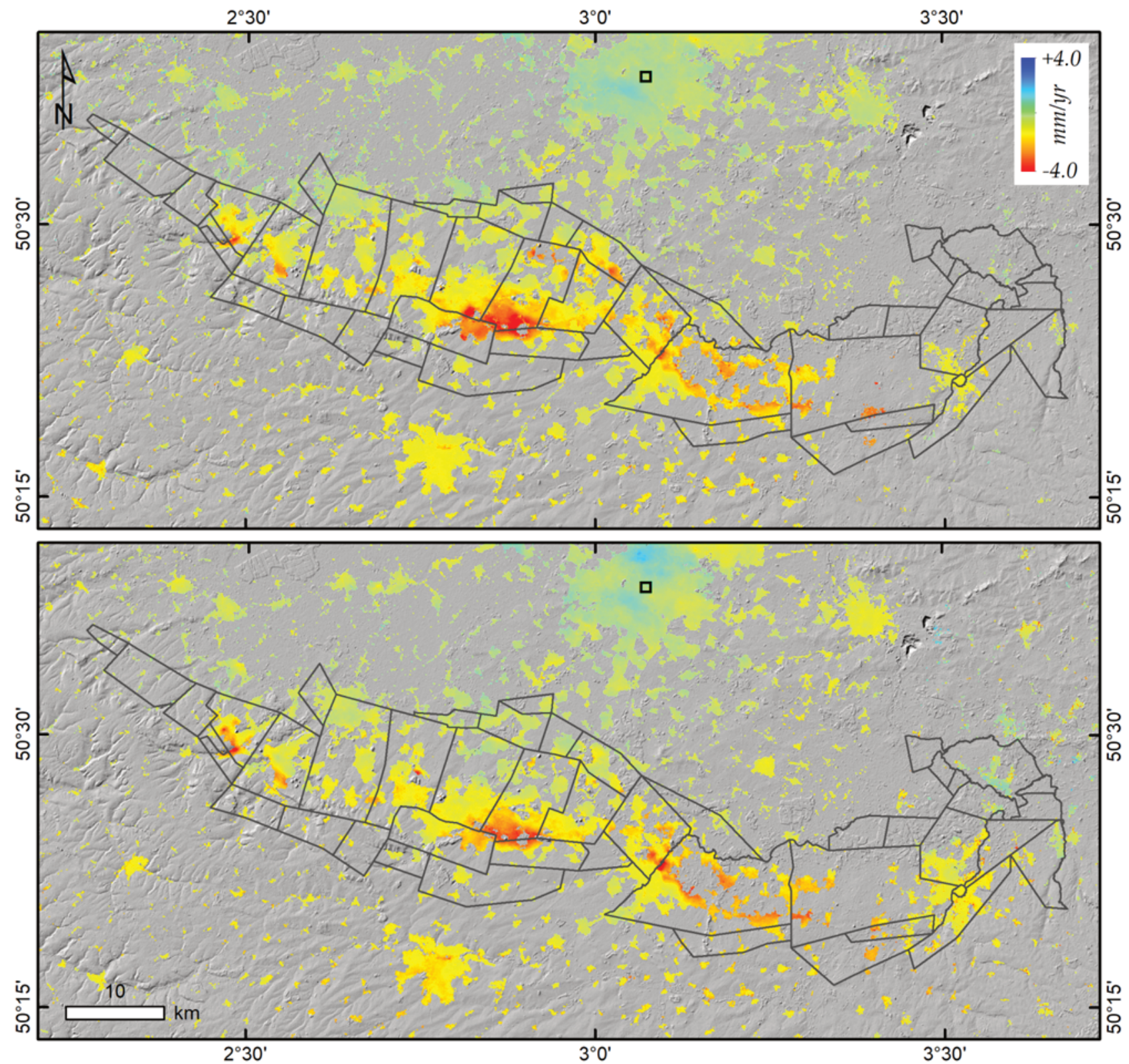

Figure 2 InSAR ground displacement rates during ERS (1995-2000) (up) and ENVISAT (2002-2010) (down) observation periods. In background a hillshade based on the AW3D30 DSM heights. Black polygons correspond to mining concessions. 


\subsection{Sentinel-1A observation period (2015-2018)}

Subsidence is still observed over the main part of the region and can reach in some places up to $5 \mathrm{~mm} /$ year (Figure 3). At the eastern part of the coal basin subsidence still takes place, while extending much further than the mining area, especially towards the southeast. Other areas with no relation to the coalfield also show significant subsidence; however, they cannot be attributed to mining-induced effects.

Natural areas, such as a riverbed, are characterised by significant subsidence, while a very localised uplift pattern is recognised within the urban area (figure 4).

All these observations point out the influence of natural and/or non-mining-induced anthropic phenomena. These phenomena should be taken into account when interpreting the origin of ground movements in the coal basin.

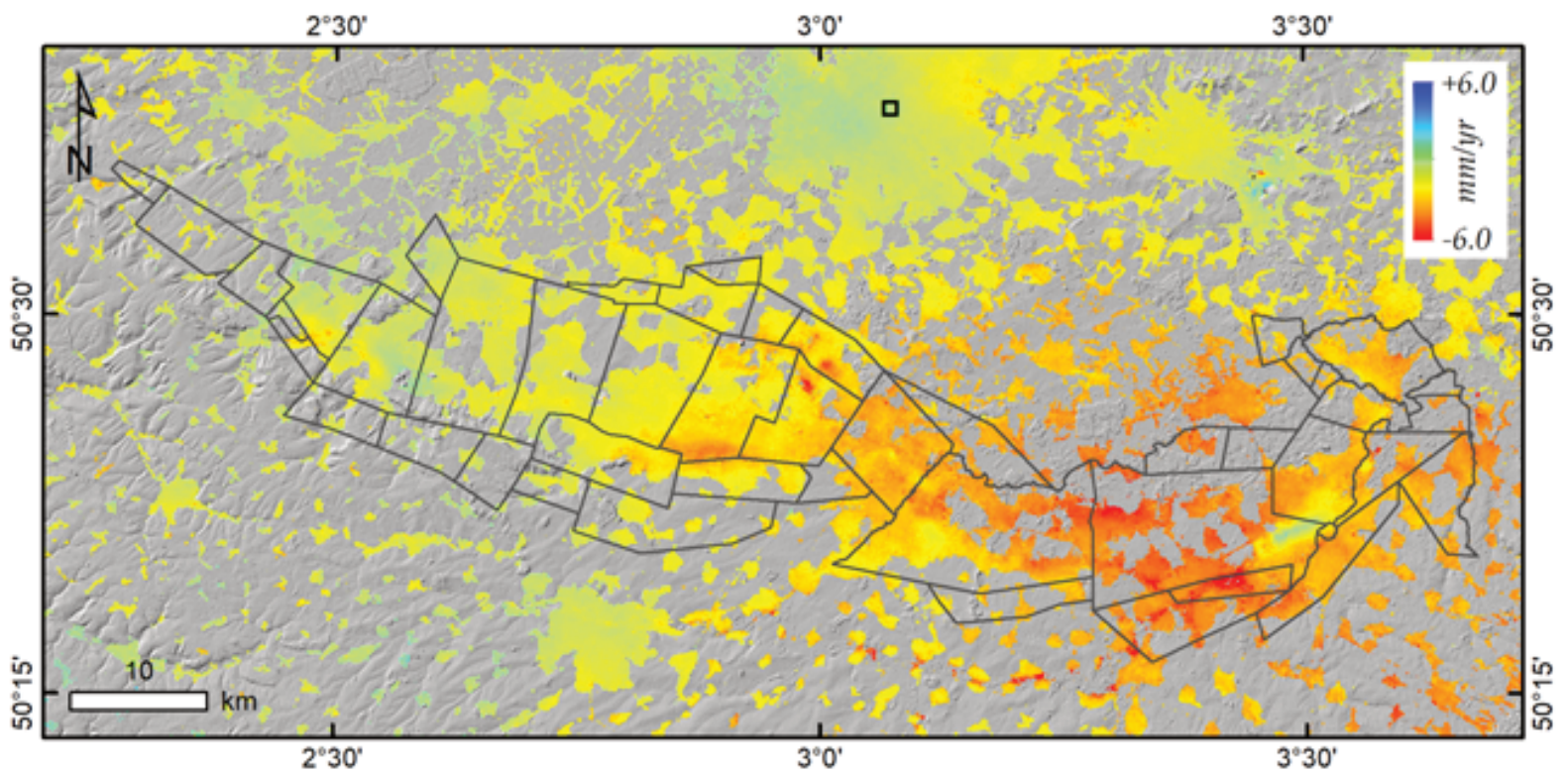

Figure 3 Sentinel-1 InSAR ground displacement rates for the period 2015-2018.

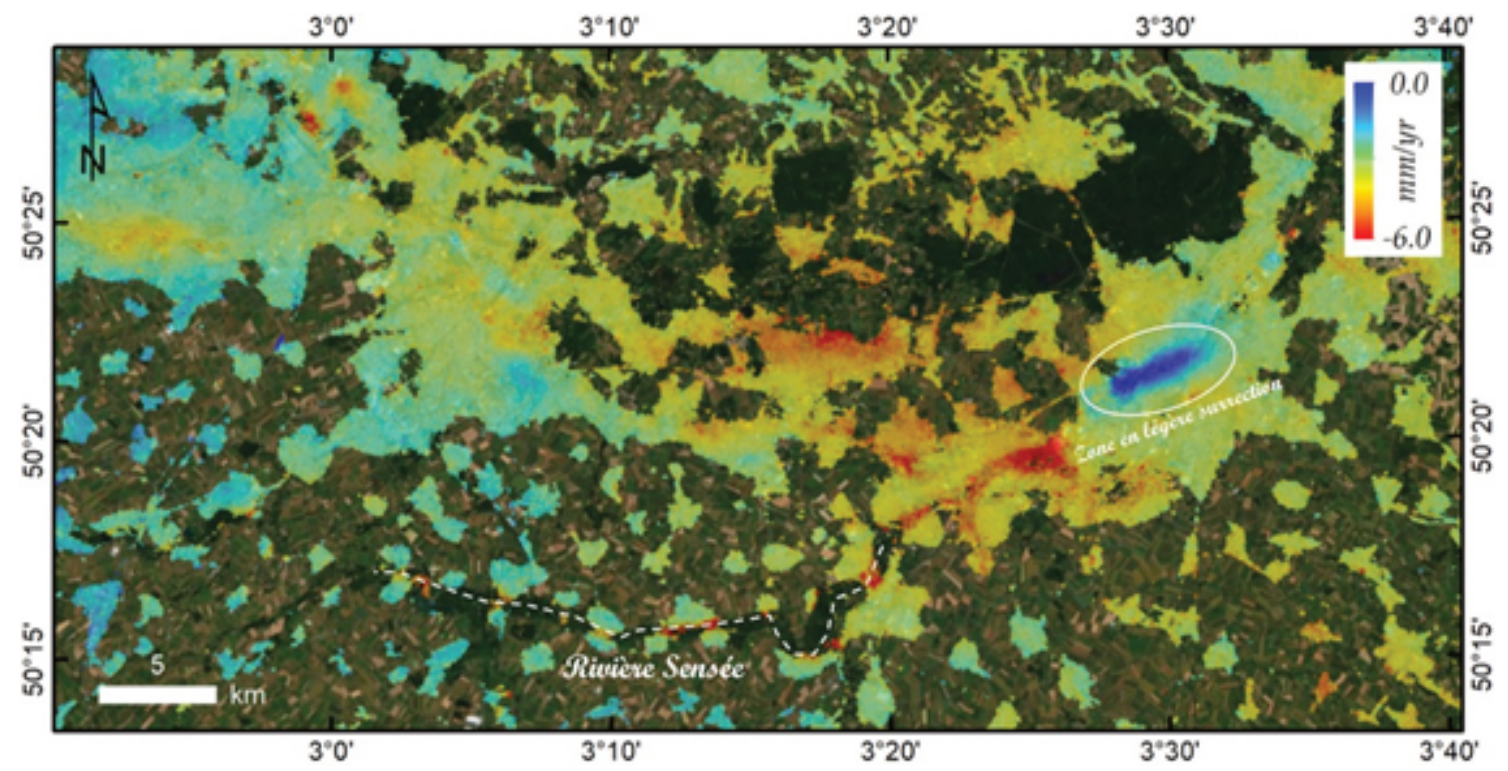

Figure 4 Subsidence along a channelled river (rivière Sensée), and localised uplift (white oval) in urban area as shown in Sentinel-1 InSAR results (period 2015-2018). Satellite imagery layer in background (source ESRI basemaps). 


\subsection{Influence of non-mining-induced phenomena}

Large and long-term geological processes, such as tectonic activity or post-glacial rebound, might generate ground movements of an estimated rate of maximum $1 \mathrm{~cm} /$ year in the Nord-Pas de Calais region (Van VlietLanoë, 1999). However, the most important natural factor remains local geology. Figure 5 shows the remarkable correlation between the boundary of geological formations and measured ground displacement rates. The coalfield is located close to the boundary between more chalky grounds (green colour, south-west of the coal basin), and more clayed grounds (orange colour, northeast of the coal basin). Subsidence is essentially observed on the clayed side of this geological boundary. The presence and amount of alluvium also plays a significant role, as can be seen by the highlight of the channelled riverbed (Figure 4).

Further data processing would be necessary to separate natural phenomena from mining-induced effects.
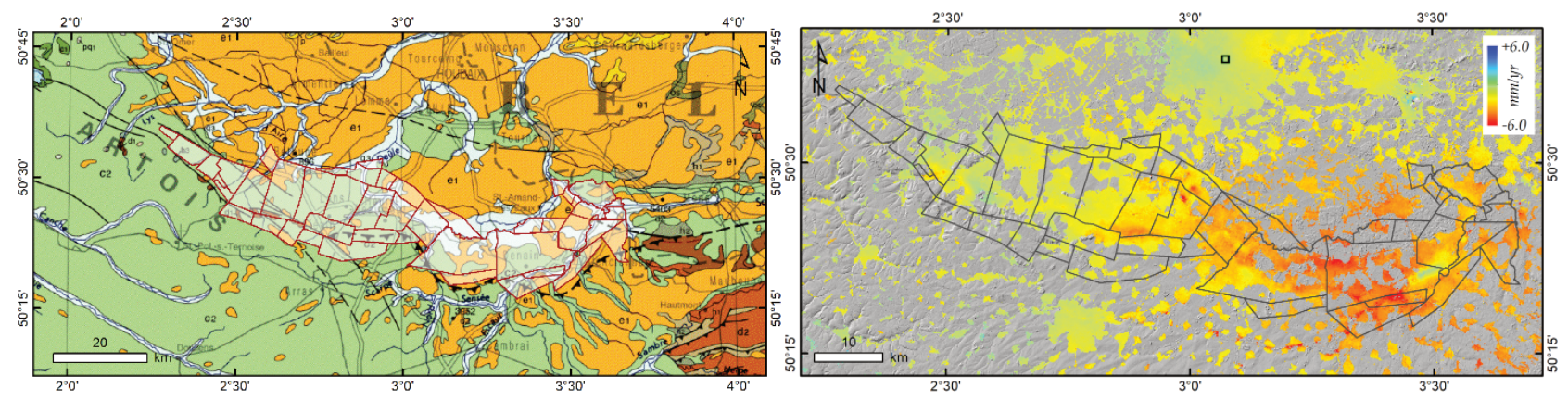

Figure 5 Correlation between geology (left) and ground vertical displacements (right, Sentinel-data)

Anthropic activities might also result in significant ground movements. Figure 6 shows a detail view of the central part of the coal basin, after filtering of the lowest displacement rates ( $<3 \mathrm{~mm} /$ year). It emphasises that most of the highest ground displacement rates are located on open pit quarries, often associated with old coal extraction waste heaps.

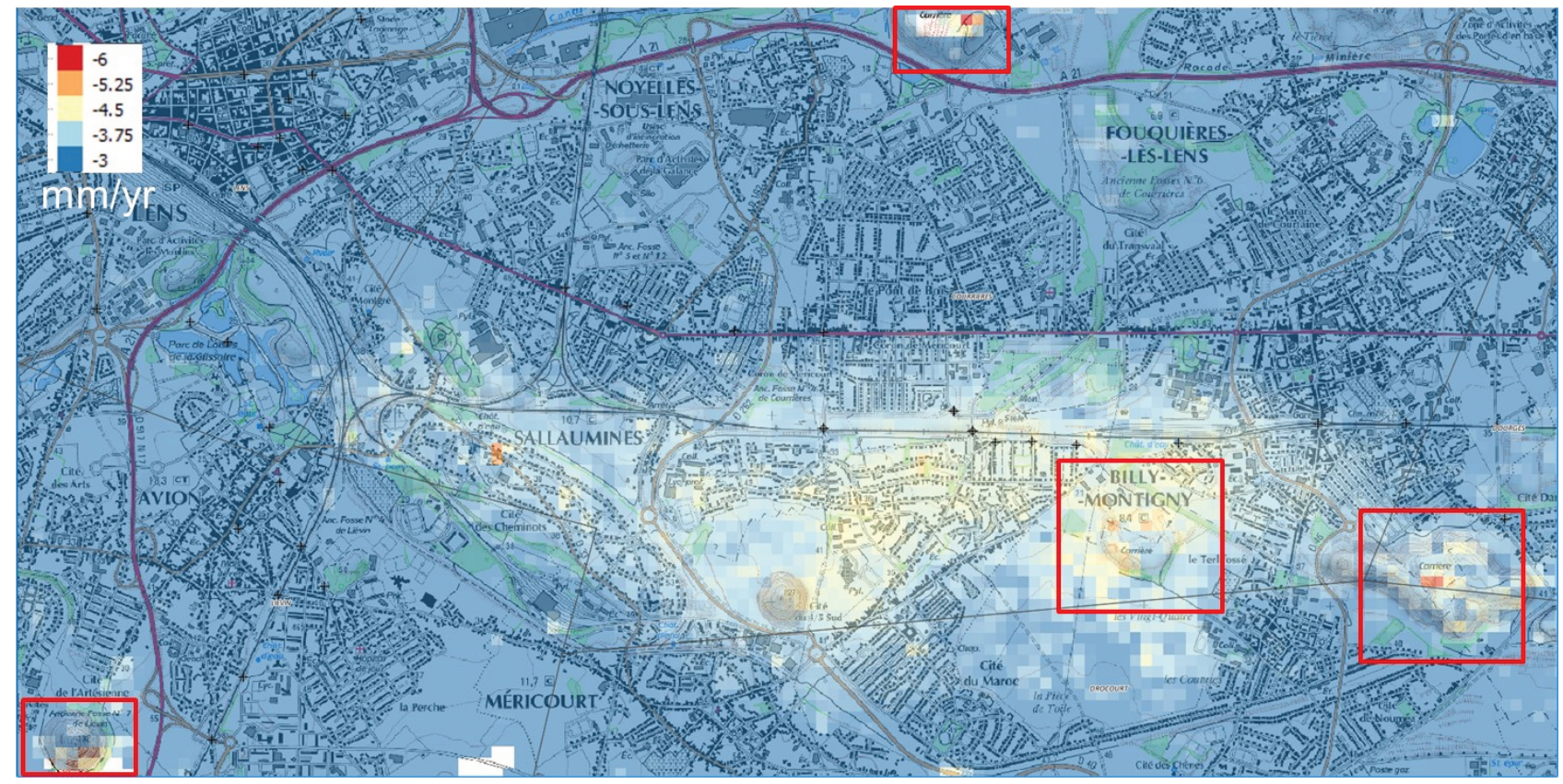

\section{Figure 6 Correlation between highest displacement rates and anthropic activities (quarries, red rectangles) - period 2015-2018}

Other anthropic factors such as ground water pumping for domestic use or forgotten underground stone quarries might also induce ground movements. 


\section{$4 \quad$ Intercomparison with levelling}

The location of the five levelling lines used for ground movements survey on the coal basin is shown in Figure 7. As previously mentioned, they do not allow for a complete coverage of the coalfield, whereas some of them are located within the underground works influence zone. Each levelling line measurement is referred to a benchmark located at or close to both ends of the line. Measurements are carried out once per year, with precision at the order of a few millimetres.

Two of the levelling lines indicate a continuous subsidence since the beginning of the measurements (example of the Lens levelling line, Figure 8a), at a rate of 1 to $4 \mathrm{~mm} /$ year. Two others do not show clear trend, with smaller displacement rates (example of the Courrières levelling line, Figure $8 \mathrm{~b}$ ). The last one shows apparent continuous uplift since the beginning of the measurements (Wallers levelling line, Figure 8c).

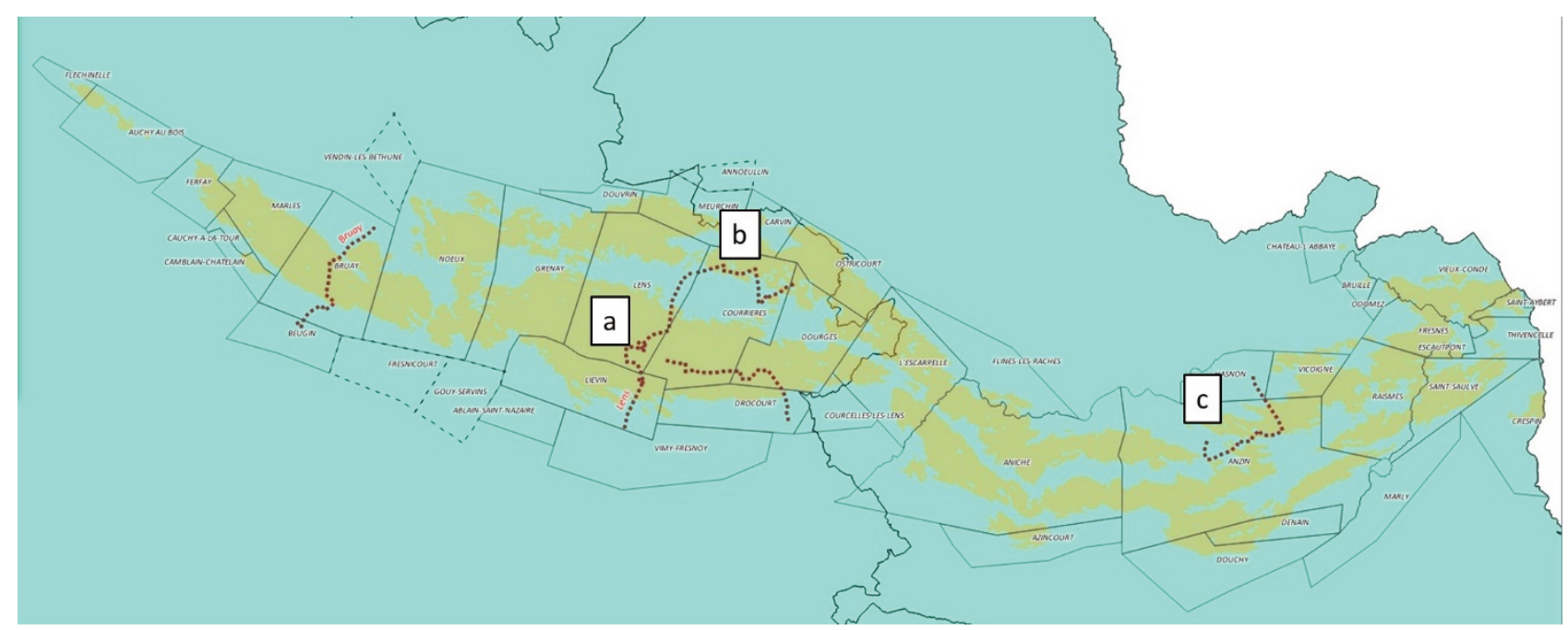

Figure 7 Situation of the 5 levelling lines in the coal basin (red dots lines) 

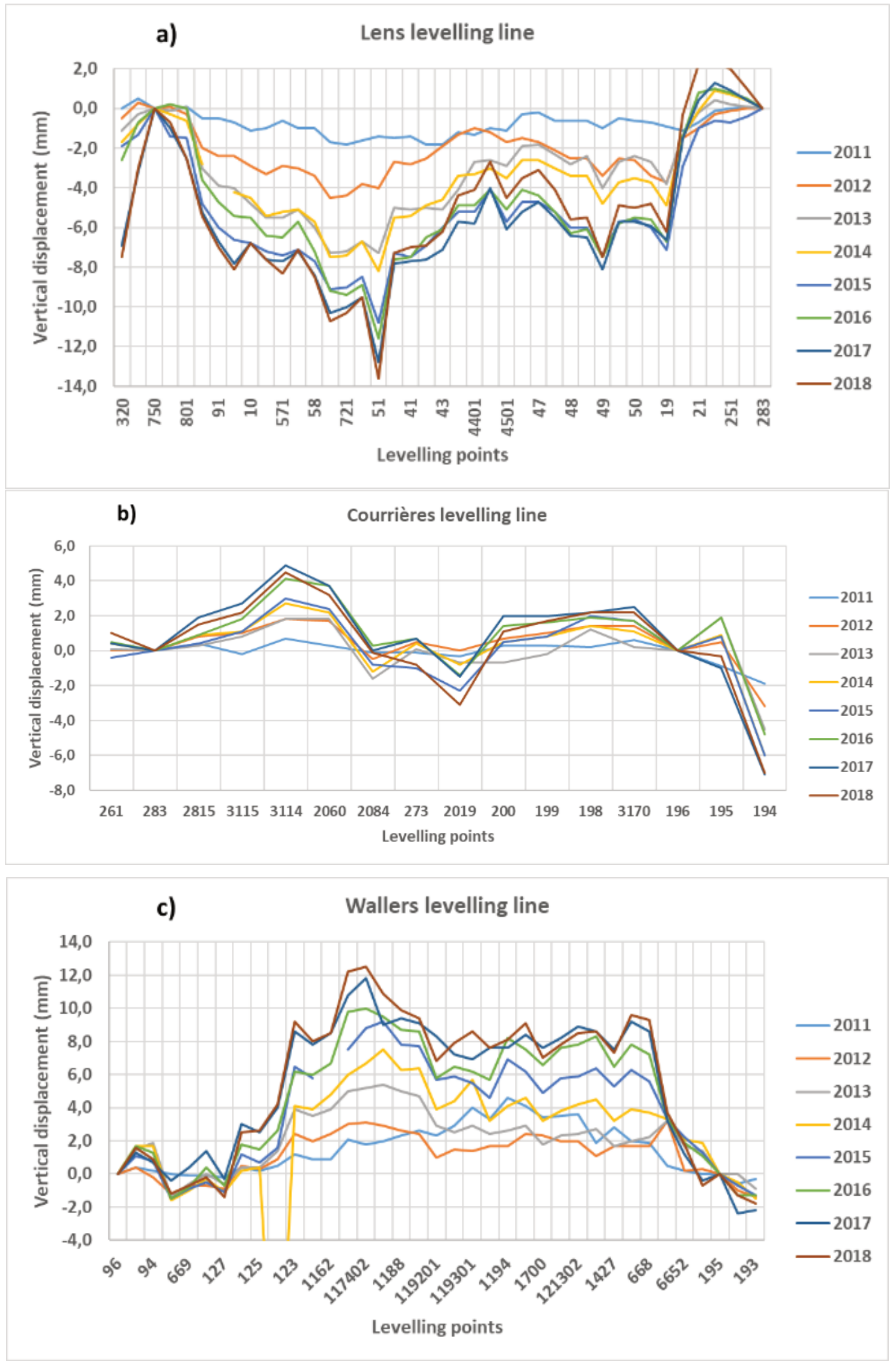

Figure 8 Displacements measured along levelling lines since 2011. Displacement reference $(0 \mathrm{~mm})$ corresponds to levelling benchmarks, located at or close to levelling lines ends. 
The intercomparison between InSAR displacement rates and levelling has been done for the period 20152018 covered by Sentinel-1 mission data.

Figure 9 presents InSAR displacement rates in the Wallers levelling line area. It shows that the benchmarks at both ends of the levelling line cannot be assumed stable during the observation period. Subsidence rates at the levelling benchmarks as high as $4.3 \mathrm{~mm} /$ year are measured. This relative movement of the levelling benchmarks generates an offset, which must be corrected when interpreting levelling data.

Moreover, the middle part of the Wallers levelling line appears to undergo slower subsidence than its ends, with displacement rates around $3 \mathrm{~mm} /$ years or less. Therefore, what was interpreted as an uplift with levelling is the result of the subsidence being faster at the ends of the levelling line than in between.

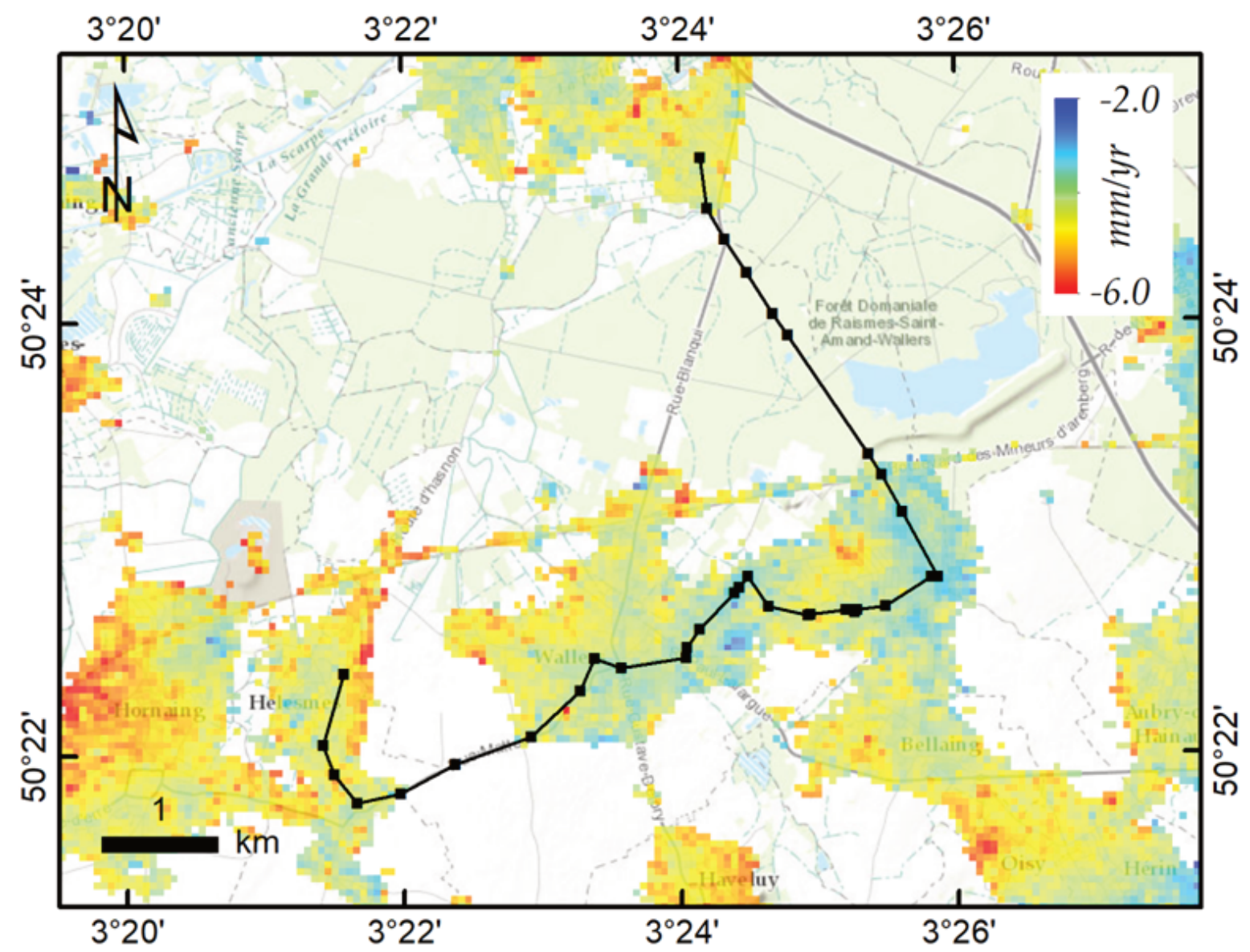

Figure 9 InSAR ground displacement rates in the Wallers levelling line area, Sentinel-1 period (20152018). World topographic map in background (source ESRI basemaps).

A more detailed comparison between InSAR and levelling data will be done for each levelling line, in order to check benchmark stability and thus the representativeness of levelling interpretation.

\section{Conclusion}

This study shows that an effective monitoring of potentially mining-induced ground movements at the scale of a coalfield needs to consider also non mining-induced mechanisms, particularly the influence of local geological conditions. The InSAR analysis offers the opportunity to cover much larger regions than with standard levelling methods, with a comparable level of precision, thus revealing potential ground movements that would not be seen by local levelling.

InSAR appears also to be a complementary tool to control the representativeness of levelling lines, by allowing the verification of levelling benchmarks stability. Unstable benchmarks may introduce bias in the interpretation of the displacements measured along the levelling line. 
Our findings underline the capability of satellite InSAR for operational survey of ground movements on abandoned coalfields.

\section{Acknowledgements}

The authors would like to thank the French Ministry for the Ecological and Inclusive Transition, for financial support. The Hauts de France Regional Directorate for Environment, Development and Housing (DREAL) is also gratefully acknowledged.

\section{References}

Banton, C, Bateson, L, McCormack, H, Holley, R, Watson, IA, Burren, R, Lawrence, D \& Cigna, F 2013, 'Monitoring post-closure large scale surface deformation in mining areas', in M Tibbett, AB Fourie \& C Digby (eds), Proceedings of the Mine Closure International conference, Australian Centre for Geomechanics, Perth, pp. 97-108.

Devleeschouwer, X, Declercq, PY, Flamion, B, Brixko, J, Timmermans, A \& Vanneste, J 2008, 'Uplift revealed by radar interferometry around Liege (Belgium): a relation with rising mining groundwater', Proceedings of the Post-Mining Symposium, Nancy, France.

Foumelis, M, Raucoules, D, Colas, B \& de Michele, M 2019, 'On the effect of interferometric pairs selection for measuring fast moving landslides', Proceedings of the International Geoscience and Remote Sensing Symposium (IGARSS 2019), Yokohama, Japan.

Hanssen, RF 2001, Radar Interferometry: data interpretation and error analysis, Springer Verlag edition.

Herrero, C, Munoz, A, Catalina, JC, Hadj-Hassen, F, Kuchenbecker, R, Spreckels, V, Juzwa, J, Bennett, S, Purvis, M, Bigby, D \& Moore, D 2012, 'Prediction and monitoring of subsidence hazards above coal mines (Presidence)', final report, RFCS Presidence project, https://op.europa.eu/en/publication-detail/-/publication/598607f4-5606-4a80-90f5-39406c498b3f/language-en

Massonnet, D \& Feigl, K 1998, 'Radar interferometry and its application to changes in the Earth's surface', Rev. Geophys., vol. 36, no. 4, p. 441.

Raucoules, D, Colesanti, C \& Carnec, C 2007, 'Use of SAR interferometry for detecting and assessing ground subsidence', Compte Rendus Geosciences, vol. 339, no. 5, p. 289

Wegmüller, U, Werner, C, Strozzi, T, Wiesmann, A, Frey O, \& Santoro, M 2016, 'Sentinel-1 Support in the GAMMA Software', Procedia Computer Science, vol. 100, pp. 1305-1312.

Van Vliet-Lanoë, H 1999, 'Evolution morphotectonique récente du bassin houiller Nord-Pas de Calais dans le cadre de l'Europe de l'Ouest', Specific report for Charbonnages de France. 